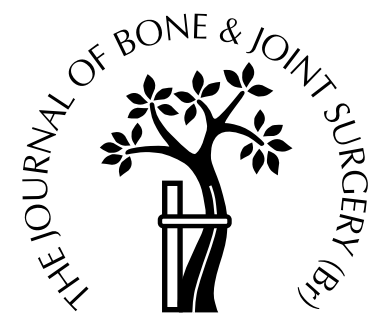

\title{
The influence of age on outcome after operation for the carpal tunnel syndrome
}

\author{
A PROSPECTIVE STUDY \\ P. Porter, B. Venkateswaran, H. Stephenson, C. C. Wray \\ From Airedale General Hospital, Keighley, England
}

D ecompression of the carpal tunnel is a common surgical procedure. Although the incidence of the carpal tunnel syndrome increases with age, there is no clear information available on the outcome of surgery in relation to age. We studied prospectively 87 consecutive patients who underwent decompression, using a validated self-administered questionnaire, and found that improvement in symptoms and function decreased with increasing age. This was most marked in patients over the age of sixty years.

J Bone Joint Surg [Br] 2002;84-B:688-91.

Received 14 March 2001; Accepted after revision 25 October 2001

Carpal tunnel syndrome (CTS) is the commonest entrapment neuropathy and is becoming increasingly prevalent. ${ }^{1-4}$ It is more common with increasing age and it is recognised that there is a deterioration in nerve-conduction in association with longevity. ${ }^{5-10}$ The outcome of surgery in relation to age has not been previously determined. We have therefore assessed prospectively the outcome of operation for CTS in 87 patients using a validated self-administered questionnaire in conjunction with clinical and neurophysiological measurements to examine the effects of age.

\section{Patients and Methods}

Between March 1999 and February 2000 we prospectively followed 91 patients with CTS who had undergone surgical decompression. The diagnosis had been made on clinical

P. Porter, FRCS (Trauma \& Orth), Specialist Registrar in Orthopaedics B. Venkateswaran, FRCS, Specialist Registrar in Orthopaedics

H. Stephenson, BSc, Senior Neurophysiology Technician

C. C. Wray, FRCS, Consultant Orthopaedic Surgeon

Department of Orthopaedics, Airedale General Hospital, Skipton Road, Keighley, West Yorkshire BD20 6TD, UK.

Correspondence should be sent to Mr P. Porter at 6 Ullswater Drive, Wetherby, West Yorkshire LS22 6YF, UK.

(C)2002 British Editorial Society of Bone and Joint Surgery 0301-620X/02/512266\$2.00

assessment and following electrophysiological studies. All patients had been screened for diabetes, thyroid disease, rheumatoid arthritis and gout, and were excluded if any of these were present. They were also ruled out if they had previously undergone the operation in the same hand, had developed CTS after trauma or pregnancy, had a history of radiculopathy of the cervical spine, or were unable to complete the self-administered questionnaire because of mental infirmity.

Each patient had been investigated by nerve-conduction studies of the motor and sensory divisions of both median and ulnar nerves before operation according to our normal protocol. The ulnar nerves were tested in order to exclude polyneuropathy and were normal in all patients. Patients were graded from 1 to 4 according to the degree of severity ( 1 severe, 4 normal). Only two with a clinical diagnosis of CTS had normal nerve-conduction tests and were excluded.

All patients completed a validated, self-administered questionnaire which assessed the severity of symptoms and their functional status. ${ }^{11}$ It consisted of questions relating to pain, paraesthesiae and numbness, according to frequency, duration and severity, and related to a range of activities of daily living. A mean score for the severity of symptoms and functional status was calculated for each patient, with a higher score representing more severe symptoms. This questionnaire has been validated statistically by the original authors for reproducibility, internal consistency and sensitivity to clinical change, and revalidated subsequently by others. ${ }^{11,12}$

Each patient had undergone open carpal tunnel decompression through a palmar incision using a tourniquet. The operation was carried out under local anaesthesia in all except three patients who required a general anaesthetic.

Patients were reviewed two weeks and six months after surgery by clinical examination and had a further nerveconduction test at the six-month review. The questionnaire was also completed again six months after operation and the changes in scores calculated. They were also asked to score satisfaction with the outcome on a scale of 1 to 5 (1, very satisfied, 5, very dissatisfied). Changes in nerveconduction values were also recorded. The data were analysed using the Mann-Whitney $U$ and Wilcoxon signed-rank tests and the Spearman rank-correlation coeffi- 


$$
\begin{aligned}
& \text { Age category } \\
& \square>60 \text { Years } \\
& \square \leqslant 60 \text { Years }
\end{aligned}
$$

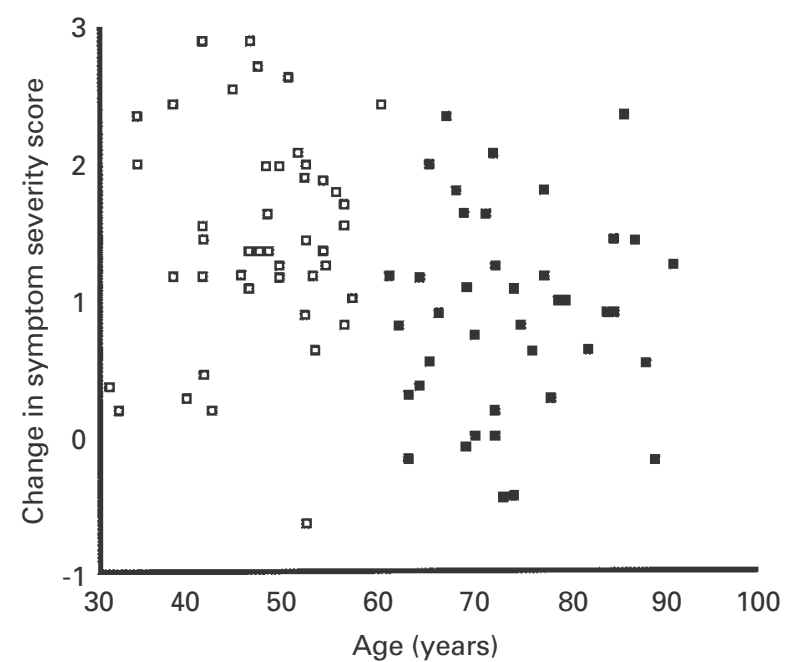

Fig. 1a

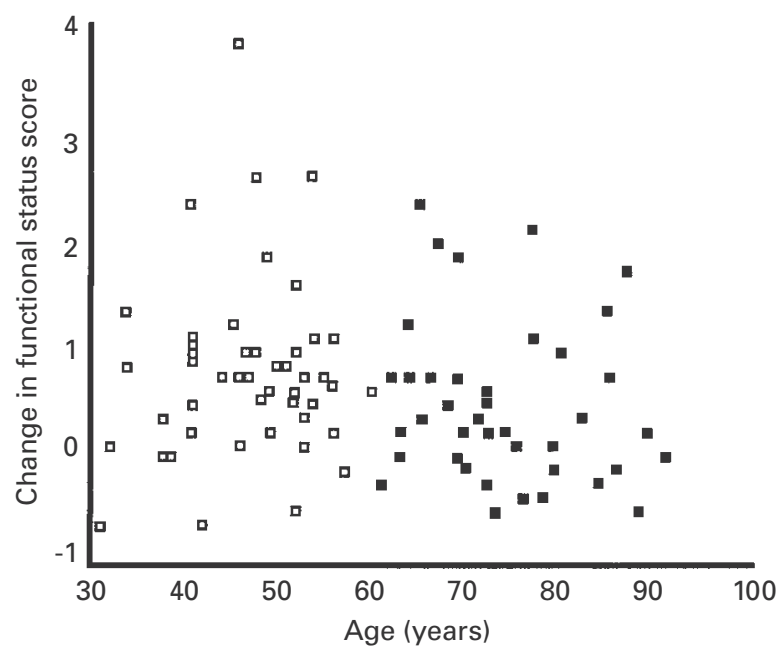

Fig. 1b

Graphs showing the correlation of the changes in a) the symptom severity score score and b) functional status score with age.

\begin{tabular}{|c|c|c|c|c|c|c|c|}
\hline \multirow{2}{*}{$\begin{array}{l}\text { Age range } \\
\text { (yrs) }\end{array}$} & \multirow{2}{*}{$\begin{array}{l}\text { Number } \\
\text { of patients }\end{array}$} & \multicolumn{3}{|c|}{ Symptom severity score } & \multicolumn{3}{|c|}{ Functional status score } \\
\hline & & Preop & Postop & Improvement & Preop & Postop & Improvement \\
\hline$\leq 50$ & 28 & 3.28 & 1.68 & 1.60 & 2.40 & 1.54 & 0.86 \\
\hline 51 to 60 & 18 & 2.83 & 1.46 & 1.37 & 2.24 & 1.52 & 0.72 \\
\hline 61 to 70 & 16 & 2.55 & 1.64 & 0.91 & 2.21 & 1.49 & 0.72 \\
\hline 71 to 80 & 16 & 2.53 & 1.73 & 0.80 & 2.16 & 1.84 & 0.32 \\
\hline$>80$ & 9 & 3.14 & 2.10 & 1.04 & 2.68 & 2.28 & 0.40 \\
\hline$\leq 50$ to $>80$ & 87 & $2.9 \pm 0.81$ & $1.68 \pm 0.74$ & 1.22 & $2.32 \pm 0.89$ & $1.66 \pm 0.75$ & 0.66 \\
\hline$\leq 60$ & 46 & $3.10 \pm 0.79$ & $1.59 \pm 0.77$ & 1.51 & $2.33 \pm 0.93$ & $1.53 \pm 0.67$ & 0.80 \\
\hline$>60$ & 41 & $2.68 \pm 0.78$ & $1.78 \pm 0.69$ & 0.90 & $2.30 \pm 0.87$ & $1.81 \pm 0.82$ & 0.49 \\
\hline
\end{tabular}

Table I. Mean symptom severity and functional outcome scores $( \pm \mathrm{SD})$ showing age-related changes after surgery for carpal tunnel syndrome in the different age groups

cient, using the statistical package SPSS version 8 (SPSS Inc, Chicago, Illinois).

\section{Results}

Four patients failed to attend for follow-up. Eighty-seven were therefore available for study, of whom there were 37 men and 50 women. Their mean age was 59.8 years ( 31 to 91); 46 were aged 60 years or less and 41 were over 60 years of age. The mean duration of preoperative symptoms was 23 months; 55 operations were on the dominant hand. The improvement in both the severity of symptoms and function was found to correlate negatively with age (Fig. 1). These differences were most significant for patients aged over 60 years. Gender, with age as a continuous variable, did not influence the outcome $(\mathrm{p}=0.997$ for improvement in the severity of symptoms, $\mathrm{p}=0.519$ for improvement in function). Furthermore, gender did not influence the outcome between those above and below the age of 60 years $(p=0.539$ for severity of symptoms, $\mathrm{p}=0.365$ for function). There was no difference in the symptom severity scores between men and women before operation, although women had worse functional scores $(p=0.031)$. Three patients developed a superficial wound infection postoperatively and required antibiotics, and a further three had tenderness of the scar which, although improving, was still present six months after surgery.

Severity of symptoms. The mean preoperative and postoperative symptom severity scores are shown in Table I. They show a considerable improvement after surgery with values similar to those which have been previously reported. ${ }^{11,13,14}$ As shown in Figure 1a the improvement in symptoms correlated negatively with age $(\mathrm{p}=0.003)$. We further analysed the data according to the age range in tenyear intervals and noted a marked decline in improvement 
beyond the age of 60 (Table I). Patients aged 60 or less had worse preoperative symptom scores than those aged more than $60(\mathrm{p}=0.023)$ (Table I). Although both groups showed a significant improvement in scores $(p<0.001$ for both groups) the older group did less well (Table I). This difference was significant $(\mathrm{p}<0.001)$. Ten patients had no improvement in the score after surgery; seven were more than 60 and three under this age.

Functional status. The improvement in functional status also showed a significant negative correlation with age $(\mathrm{p}=0.046)$ although this was less marked than for amelioration of symptoms (Fig. 1b). The difference in functional improvement was again significant between the two groups $(\mathrm{p}=0.034)$ but was less notable in the older patients (Table I). There was no difference in the preoperative functional scores between the two groups $(\mathrm{p}=0.997)$. Of the 18 patients who showed no improvement, 13 were aged over 60. Five of these also showed no change in the symptom severity score. Only one patient aged less than 60 had no improvement in either symptom severity or functional status.

Nerve-conduction tests. Both age groups showed a significant improvement in nerve conduction after operation. Those patients aged 60 or less improved from a preoperative median value of grade 2 (interquartile range (IQR) 1 to 2) to a postoperative value of 3 (IQR 2 to 4; $\mathrm{p}=0.001)$. The improvement in the older group was from 1 (IQR 1 to 1 ) to 2 (IQR 1.5 to $2.5 ; \mathrm{p}=0.001$ ), but was significantly less than in the younger group $(\mathrm{p}=0.027)$. There was no correlation between the nerve-conduction values measured before operation and the severity of symptons or of the functional scores.

Using a satisfaction score ten patients expressed dissatisfaction after decompression, and a further ten scored the result as neutral, neither satisfied nor dissatisfied. Seven of the dissatisfied and seven of the neutral patients were aged over 60 (Table II). Of the seven in the older group who were dissatisfied, six had no improvement in either the symptom or the functional scores. Of the three patients aged less than 60 who were dissatisfied, all had little or no improvement in symptom severity, and two in functional status. There was no difference in the duration of preoperative symptoms between the two age groups. Those aged over 60 had a slightly shorter duration of symptoms, but this was not statistically significant.

\section{Discussion}

Previous studies which have reported the results of surgery for CTS have used a range of clinical and neurophysiological measurements; the results have been variable and often contradictory. ${ }^{15-19}$ Carpal tunnel decompression is a common procedure undertaken with the aim of alleviating symptoms. Outcome measures must therefore reflect this. Clinical examination and neurophysiological testing, although helpful in diagnosis, do not necessarily reflect the
Table II. Patient satisfaction rating for outcome after surgery for carpal tunnel syndrome

\begin{tabular}{|c|c|c|c|c|c|c|}
\hline & \multicolumn{2}{|l|}{ Satisfied } & \multicolumn{2}{|c|}{ Dissatisfied } & \multicolumn{2}{|l|}{ Neutral } \\
\hline & Number & $\%$ & Number & $\%$ & Number & $\%$ \\
\hline All patients & 67 & 77.0 & 10 & 11.5 & 10 & 11.5 \\
\hline$\leq 60$ years & 40 & 87.0 & 3 & 6.5 & 3 & 6.5 \\
\hline$>60$ years & 27 & 65.8 & 7 & 17.1 & 7 & 17.1 \\
\hline
\end{tabular}

severity of symptoms and cannot reliably be used to measure outcome. ${ }^{13,17,18,20}$ The questionnaire assessing severity of symptoms and functional status used in our study has been statistically validated and was completed by the patients without the direct involvement of the clinician. Operation for CTS produces symptomatic improvement in $90 \%$ to $95 \%$ of patients. ${ }^{17,21,22}$ Improvement after surgery has been shown to be largely complete within three to six months. Our results at six months are therefore likely to be an accurate reflection of the final outcome. ${ }^{11,13,14}$ Similar rates of improvement were also seen in our study, with $90 \%$ of patients having symptomatic improvement six months after operation. There was improvement in functional status in $82 \%$. Most of those patients who failed to show functional improvement were in the older group. One in three over 60 years of age failed to express satisfaction with the results of surgery. There is conflicting evidence on the effect of the duration of symptoms on surgical outcome although most studies suggest that it has no bearing on the result. $^{15,23,24}$ In our patients, however, there was no significant difference in the preoperative duration of symptoms.

It has been reported previously that women complain more of carpal tunnel symptoms than men. ${ }^{25}$ We found that women had the same preoperative level of symptoms as men, although they complained more of functional limitations. We found no gender-related difference in improvement in symptoms or functional status after surgery in the group as a whole, or in either of the age groups. Previous authors using the same questionnaire have shown that the symptom severity and functional scores before operation did not correlate with the nerve-conduction values, or with improvement in the scores after surgery. ${ }^{13}$ Our results agree with this.

The improvement in both scores declined with age. These changes are not related to gender, the severity of preoperative symptoms, or the results of neurophysiological testing. We found that patients over 80 years of age showed more improvement in the symptom severity score than those aged between 61 and 80 years and had better functional status scores than those aged between 71 and 80 years. This group was, however, very small (nine patients) and the differences were not marked.

There was no age group which did not improve after surgery. Even the very elderly showed a significant improvement in the symptom severity score and although their level of satisfaction was lower than in younger 
patients, surgery was still worthwhile. The elderly should be told that operation is only likely to produce modest improvement and that they may not be satisfied with the result. Age is a clear factor affecting the outcome after carpal tunnel decompression.

We wish to thank Mrs Sue Marshall for help with data processing, Ms Moira Geldard for administrative help, and Miss Wendy Parsons, MPH, for help with statistical analysis.

No benefits in any form have been received or will be received from a commercial party related directly or indirectly to the subject of this article.

\section{References}

1. Stevens JC, Sun S, Beard CM, O'Fallon WM, Kurland LT. Carpal tunnel syndrome in Rochester, Minnesota, 1961 to 1980 . Neurology 1988;38:134-8

2. De Krom MC, Knipschild PG, Kester AD, et al. Carpal tunnel syndrome: prevalence in the general population. J Clin Epidemiol 1992;45:373-6.

3. Tanaka S, Wild DK, Seligman PJ, et al. The US prevalence of selfreported carpal tunnel syndrome: 1988 national health interview survey data. Am J Public Health 1994;84:1846-8.

4. Nordstrom DL, DeStefano F, Vierkant RA, Layde PM. Incidence of diagnosed carpal tunnel syndrome in a general population. Epidemiology 1998;9:342-5.

5. Ferry S, Pritchard T, Keenan J, Croft P, Silman AJ. Estimating the prevalence of delayed median nerve conduction in the general population. Br J Rheumatol 1998;37:630-5.

6. Lam N, Thurston A. Association of obesity, gender, age and occupation with carpal tunnel syndrome. Aust $N$ Z J Surg 1998;68:190-3.

7. Nathan PA, Meadows KD, Doyle LS. Relationship of age and sex to sensory conduction of the median nerve at the carpal tunnel and association of slowed conduction with symptoms. Muscle Nerve 1988;11:1149-53.

8. Hennessey WJ, Falco FJ, Braddom RL, Goldberg G. The influence of age on distal latency comparisons in carpal tunnel syndrome. Muscle Nerve 1994;17:1215-7.

9. Salerno DF, Franzblau A, Werner RA, et al. Median and ulnar nerve conduction studies among workers: normative values. Muscle Nerve 1998;21:999-1005.

10. Winn FJ, Putz-Anderson V. Vibration thresholds as a function of age and diagnosis of carpal tunnel syndrome: a preliminary report. Exp Aging Res 1990;16:221-4.
11. Levine DW, Simmons BP, Koris MJ, et al. A self-administered questionnaire for the assessment of severity of symptoms and functional status in carpal tunnel syndrome. J Bone Joint Surg [Am] 1993;75-A:1585-92.

12. Padua R, Padua L, Romanini E, et al. Italian version of the 'Boston carpal tunnel' questionnaire: preliminary valuation. Ital J Orth Trauma 1998;24:121-9.

13. Mondelli M, Reale F, Sicurelli F, Padua L. Relationship between the self-administered Boston questionnaire and electrophysiological findings in follow-up of surgically-treated carpal tunnel syndrome. $J$ Hand Surg $[\mathrm{Br}]$ 2000;25:128-34.

14. Atroshi I, Gummesson C, Johnsson R, Sprinchorn A. Symptoms, disability, and quality of life in patients with carpal tunnel syndrome. J Hand Surg [Am] 1999;24:398-404.

15. Wintman BI, Winters SC, Gelberman RH, Katz JN. Carpal tunnel release: correlations with preoperative symptomatology. Clin Orthop 1996;326:135-45.

16. DeStefano F, Nordstrom DL, Vierkant RA. Long-term symptom outcomes of carpal tunnel syndrome and its treatment. J Hand Surg [Am] 1997;22:200-10.

17. Glowacki KA, Breen CJ, Sachar K, Weiss AP. Electrodiagnostic testing and carpal tunnel release outcome. J Hand Surg Am 1996;21:117-21.

18. Higgs PE, Edwards DF, Martin DS, Weeks PM. Relation of preoperative nerve-conduction values to outcome in workers with surgically treated carpal tunnel syndrome. J Hand Surg [Am] 1997;22:216-21.

19. Braun RM, Jackson WJ. Electrical studies as a prognostic factor in the surgical treatment of carpal tunnel syndrome. J Hand Surg [Am] 1994;19:893-900.

20. Amadio PC, Silverstein MD, Ilstrup DM, Schlek CD, Jensen LM. Outcome assessment for carpal tunnel surgery: the relative responsiveness of generic, arthritis-specific, disease-specific, and physical examination measures. J Hand Surg [Am] 1996;21:338-46.

21. Nancollas MP, Peimer CA, Wheeler DR, Sherwin FS. Long-term results of carpal tunnel release. J Hand Surg [Br] 1995;20:470-4

22. Concannon MJ, Gainor B, Petroski GF, Puckett CL. The predictive value of electrodiagnostic studies in carpal tunnel syndrome. Plast Reconstr Surg 1997;100:1452-8.

23. Nolan WB, Alkaitis D, Glickel SZ, Snow S. Results of treatment of severe carpal tunnel syndrome. J Hand Surg [Am] 1992;17:1020-3.

24. Choi SJ, Ahn DS. Correlation of clinical history and electrodiagnostic abnormalities with outcome after surgery for carpal tunnel syndrome. Plast Reconstr Surg 1998;102:2374-80.

25. Padua L, Padua R, Aprile I, Tonali P. Italian multicentre study of carpal tunnel syndrome: differences in the clinical and neurophysiological features between male and female patients. J Hand Surg $[\mathrm{Br}]$ $1999 ; 24: 579-82$. 